\title{
RENTABILIDADE ECONÔMICA DO MANEJO DE BAIXO IMPACTO EM FLORESTAS TROPICAIS: UM ESTUDO DE CASO
}

\author{
Romano Timofeiczyk Júnior ${ }^{1}$, Versides Sebastião M. da Silva ${ }^{2}$, Ricardo Berger ${ }^{1}$, \\ Roberto Antonio Ticle de Melo e Sousa ${ }^{2}$ \\ ${ }^{1}$ Eng. Florestal, Dr., Depto. de Economia Rural e Extensão, UFPR, Curitiba, PR, Brasil - romano@ufpr.br - berger@bighost.com.br \\ ${ }^{2}$ Eng. Florestal, Dr., Faculdade de Engenharia Florestal, UFMT , Cuiabá, MT, Brasil - versides@terra.com.br - ratms@terra.com.br \\ Recebido para publicação: 17/10/2007 - Aceito para publicação: 12/03/2008
}

\begin{abstract}
Resumo
Este estudo teve o objetivo de analisar a rentabilidade econômica do manejo de baixo impacto nas florestas tropicais em cenários distintos de investimento em terra e de produtividade da floresta. Os dados foram obtidos em uma fazenda situada no município de Marcelândia, estado do Mato Grosso, que explora a floresta tropical sob regime de manejo e comercializa as toras para indústrias da região. Os resultados demonstraram que a terra apresenta grande importância na rentabilidade do manejo. Considerando esse investimento, a Taxa Interna de Retorno (TIR) variou de $0,97 \%$ a 3,77\%, valores muito abaixo da Taxa Mínima de Atratividade (TMA) de 12\% ao ano. O Valor Presente Líquido (VPL) mostrou-se muito sensível ao valor da terra, oscilando de $-\mathrm{R} \$ 10.993 .508$ a $-\mathrm{R} \$ 43.139 .242$. A exclusão do valor da terra do investimento promoveu uma melhora significativa na TIR e no VPL, demonstrando o grande impacto que esse recurso tem na análise de projetos de manejo. Ao se desconsiderar o investimento em terra, os valores da TIR variaram de $12,68 \%$ a $26,23 \%$ e o VPL variou de $\mathrm{R} \$ 210.240$ a $\mathrm{R} \$ 4.274 .460$.
\end{abstract}

Palavras-chave: Rentabilidade econômica; floresta tropical; manejo florestal.

\begin{abstract}
Economic profitability of low impact management in Tropical forests: a case study. This paper had as objective to analyze economic viability of the management of low impact on tropical forests in different scenarios of investment in land and productivity of the forest. Data were obtained from a farm located in the municipality of Marcelândia, State of Mato Grosso, which harvests a tropical forest via RIL as a proxy to a sustainable forest management system and sells timber for wooden industries established in its region. The results showed that the land presents great importance in the profitability of management. Considering this investment, the Internal Rate of Return (IRR) ranged from $0,97 \%$ to $3,77 \%$, well below the values of rate of Minimum to (MRI) of $12 \%$ per year. The Net Present Value (NPV) was very sensitive to the value of the land, ranging from R\$ 10.993 .508 to - R\$ 43.139.242. The exclusion of the value of the land of the investment promoted a significant improvement in the IRR and NPV, demonstrating the impact that this feature is in the analysis of management project. When disregard the investment in land, the values of TIR ranged from 12,68\% to $26,23 \%$ and the NPV ranged from $\mathrm{R} \$ 210.240$ to $\mathrm{R} \$ 4.274 .460$.

Keywords: Economic profitability; tropical forest; Forest management.
\end{abstract}

\section{INTRODUÇÃO}

Durante as últimas décadas, observou-se um aumento da conscientização sobre o valor que os recursos naturais renováveis, principalmente as florestas, exercem sobre os seus habitantes. Tem-se percebido que os recursos são finitos, e se não forem criados mecanismos para o aproveitamento sustentável, a sociedade sofrerá conseqüências ambientais graves num futuro próximo.

A necessidade da utilização racional dos recursos naturais fez aumentarem as pressões nacionais e internacionais sobre a floresta amazônica, sendo fundamental a utilização de mecanismos para o aproveitamento sustentável. Esse fato confere ao manejo florestal sustentado um importante instrumento para compatibilizar o desenvolvimento ambiental, social e econômico, que tem como objetivo manter a floresta em condições de abastecer a demanda das futuras gerações. 
Embora as pesquisas sobre manejo florestal na Amazônia brasileira estejam sendo desenvolvidas desde 1958, portanto há 40 anos, a descontinuidade dessas pesquisas não permite que se tenham ainda informações concretas envolvendo um ciclo completo de corte. Para verificar se uma determinada prática florestal é sustentável, é preciso recorrer a uma comparação de atributos entre dois momentos situados no tempo: entre passado e presente, entre presente e futuro. Para isso, é necessária uma grande quantidade de informações que demonstrem o efeito da exploração e da atividade pós-exploratória na regeneração da floresta, o que é difícil, já que as florestas manejadas encontram-se ainda no primeiro ciclo de corte (ACSELRAD,1995).

Entretanto, segundo Cunha (2003), na prática é difícil definir o que se entende por manejo florestal sustentável. As interações entre flora e fauna em um ecossistema florestal são complexas e difíceis de entender, haja vista que ações tomadas no presente somente serão mostradas com mais evidências em sucessivos ciclos de corte, que é o período decorrido entre dois momentos de exploração na mesma área.

As pesquisas desenvolvidas para comprovar a viabilidade do manejo florestal madeireiro têm privilegiado principalmente a verificação de aspectos técnico-científicos. No manejo florestal, a etapa mais desenvolvida é o sistema de exploração de impacto reduzido, porém as conseqüências dessa exploração no ecossistema são desconhecidas. As análises econômicas ainda estão limitadas a experiências em projetos demonstrativos, carecendo de informações sobre o comportamento econômico em escala empresarial e envolvendo mais de um ciclo de corte (SOUZA, 2002).

Portanto, um dos grandes obstáculos para determinar a viabilidade econômica do manejo sustentado de baixo impacto é a falta de informações consistentes. Apesar dessas limitações, esse trabalho procurou preencher a lacuna existente sobre a rentabilidade econômica do manejo de florestas tropicais, confrontando os indicadores de rentabilidade com um e dois ciclos de produção em cenários distintos de investimento em terra e produtividade da floresta.

\section{MATERIAL E MÉTODOS}

\section{Área de estudo}

A descrição da floresta que gerou os dados para a realização deste trabalho foi fornecida pelo Projeto de Apoio ao Manejo Florestal Sustentável na Amazônia - MMA/IBAMA/PPG7, Projeto HuaiaMissu. A floresta está localizada no quadrilátero formado pelas coordenadas geográficas de $10^{\circ} 36^{\prime} 03$ ' e $11^{\circ} 07^{\prime} 35^{\prime}$ " de latitude Sul e $53^{\circ} 25^{\prime} 50^{\prime \prime}$ e $54^{\circ} 03^{\prime} 40^{\prime}$ ' de longitude Oeste de Greenwich, no município de Marcelândia, estado de Mato Grosso, a $873 \mathrm{~km}$ de Cuiabá.

A área total da Fazenda é de 145.000 ha, e a Área de Manejo Florestal (AMF) é de 116.348 ha. Cada Unidade de Produção Anual (UPA), que é a área a ser explorada anualmente, tem 4.653,92 ha. A floresta produz toras de madeira tropical, e o principal destino da produção são as indústrias de laminados e serrados dos municípios de Sinop e Marcelândia, no Mato Grosso.

\section{Fonte de dados primários}

A empresa responsável pela execução do manejo florestal e pela comercialização das toras forneceu os dados de todos os recursos físicos e financeiros, assim como as receitas auferidas pela venda da produção.

A realização do trabalho foi baseada na Instrução Normativa 04 do Ministério do Meio Ambiente (MMA), que regulamenta o manejo florestal em escala empresarial na região amazônica, sendo considerados dois ciclos de corte de 25 anos cada um. A metodologia utilizada está representada na figura 1 , na qual cada quadrado representa uma UPA, do total de 25 UPAs, sendo que no primeiro ciclo de corte são exploradas as UPAS de número 1 a 25 . Após o início do segundo ciclo de corte, cujo sistema de manejo florestal já está implantado, retorna-se à primeira UPA, representada pela simbologia $1 \mathrm{~s}$. Esse procedimento repete-se ao longo dos anos.

\section{Formação do fluxo de caixa}

Utilizou-se o modelo de fluxo de caixa descontado, o qual considera a variação que o dinheiro possui ao longo do tempo, sendo o melhor método para tomadas de decisões (HORNGREN, 1985). De acordo com o autor, um aspecto importante do fluxo de caixa descontado é seu enfoque nas entradas e saídas de caixa, e não no lucro líquido, tal como calculado no sentido de contabilidade pelo regime de competência. Para a presente análise, o fluxo de caixa foi dividido em duas etapas. A primeira contém os 
investimentos/re-investimentos, capital de giro, custos fixos e custos variáveis. Os componentes dessa etapa são denominados de saídas de caixa e representam todas as despesas da empresa no decorrer da sua vida útil. A segunda etapa contém a receita bruta, a qual pode ser denominada de entrada de caixa, compondo as receitas da empresa no decorrer do período considerado.

\begin{tabular}{|c|c|c|c|c|c|c|c|c|c|}
\hline 1 & 2 & 3 & 4 & 5 & 6 & 7 & 8 & 9 & 10 \\
\hline 11 & 12 & 13 & 14 & 15 & 16 & 17 & 18 & 19 & 20 \\
\hline 21 & 22 & 23 & 24 & 25 & $1 \mathrm{~s}$ & $2 \mathrm{~s}$ & $3 \mathrm{~s}$ & $4 \mathrm{~s}$ & $5 \mathrm{~s}$ \\
\hline $6 \mathrm{~s}$ & $7 \mathrm{~s}$ & $8 \mathrm{~s}$ & $9 \mathrm{~s}$ & $10 \mathrm{~s}$ & $11 \mathrm{~s}$ & $12 \mathrm{~s}$ & $13 \mathrm{~s}$ & $14 \mathrm{~s}$ & $15 \mathrm{~s}$ \\
\hline $16 \mathrm{~s}$ & $17 \mathrm{~s}$ & $18 \mathrm{~s}$ & $19 \mathrm{~s}$ & $20 \mathrm{~s}$ & $21 \mathrm{~s}$ & $22 \mathrm{~s}$ & $23 \mathrm{~s}$ & $24 \mathrm{~s}$ & $25 \mathrm{~s}$ \\
\hline
\end{tabular}

Figura 1. Unidades de produção anual (UPA) nos dois ciclos de corte.

Figure 1. Annual production units in the two cutting cicles.

\section{Saídas de caixa}

Investimento e re-investimento

Os bens móveis e imóveis necessários para executar o manejo sustentado em escala empresarial foram fornecidos pela empresa e estão descritos na tabela 1. O orçamento para os referidos bens foram obtidos nos fornecedores especializados, contendo o frete e a montagem na Fazenda, quando necessário.

Tabela 1. Bens necessários para a execução do manejo e suas respectivas vidas úteis.

Table 1. Necessary possessions for the management's execution and their respective useful life.

\begin{tabular}{lc}
\hline Item & Vida útil (anos) \\
\hline Terra & - \\
Caminhões & 5 \\
Tratores de pneu (4x4) & 10 \\
Trator de esteira & 10 \\
Motoniveladora & 10 \\
Pá Carregadeira 55C & 10 \\
Pá Carregadeira W20 & 10 \\
Geradores Pequenos 12KVA & 10 \\
Geradores Médios 22 KVA & 10 \\
Geradores Grandes 60 KVA & 10 \\
Motos XLR 125 & 5 \\
Camionete & 5 \\
Computadores & 5 \\
Infra-estrutura & 25 \\
Móveis & 10 \\
\hline Fonte: Timofeiczyk (2004).
\end{tabular}

Os re-investimentos são as aquisições necessárias para a substituição das máquinas, equipamentos, veículos, infra-estrutura, móveis e computadores já deteriorados ou ultrapassados ao longo do horizonte de planejamento. Os re-investimentos foram efetuados no espaço de tempo pré-determinado pela vida útil desses bens.

\section{Capital de giro}

De acordo com Noronha (1987), nos projetos de investimentos as despesas antecedem as receitas. Essa defasagem temporal implica a necessidade do capital de giro, que é constituído pelo estoque de matéria-prima e componentes, além de outros itens necessários à operação do projeto.

Foi considerado como capital de giro o valor referente aos gastos anuais da atividade préexploratória, tendo em vista que essa atividade ocorre, em média, um ano antes da exploração. As despesas relativas a seis meses da atividade exploratória também foram consideradas como capital de giro, em função da diferença temporal que há entre a exploração, a venda e o recebimento do valor devido. 


\section{Custos operacionais}

Os custos operacionais ocorrem após a fase de implantação do projeto e são necessários para o seu pleno funcionamento. Para a execução do Plano de Manejo Florestal Sustentável (PMFS), é indispensável a elaboração do Plano Operacional Anual (POA), que deve conter todas as atividades florestais da empresa num determinado ano. Tais custos, classificados como variáveis, são correspondentes às operações existentes na atividade pré-exploratória, exploratória e pós-exploratória.

Os custos fixos incluem todas as formas de remuneração decorrentes da manutenção dos recursos fixos. Em razão da diferença de idade existente entre os vários bens móveis e imóveis, optou-se por utilizar o valor de aquisição. Os componentes dos custos fixos são Imposto Territorial Rural (ITR), custos administrativos (salários e encargos, manutenção da sede da fazenda, manutenção de caminhões e máquinas, manutenção de veículos de apoio, manutenção de estradas principais, manutenção de pontes, despesas administrativas e manutenção do escritório de Sinop) e depreciação. Ressalte-se que a depreciação não constitui fluxo de caixa, porém é importante para evitar pagamento indevido de Imposto de Renda.

\section{Entradas de caixa}

A entrada do fluxo de caixa é dada pela Receita Bruta (faturamento) que a empresa tem com a venda da produção de toras. Após o término da vida útil dos bens móveis e imóveis, há um valor de mercado, definido como valor residual, que é tido como uma receita no fluxo de caixa. O valor residual corresponde ao valor de mercado pago pelo bem após o término de sua vida útil. Esses valores foram sugeridos pelos fabricantes e pelo mercado local, tendo em vista que não há aferições reais realizadas na região.

Após o término do horizonte de planejamento considerado, dar-se-á o retorno do capital de giro investido inicialmente. Ele ocorre quando se considera o valor da terra no investimento.

\section{Métodos de análise de investimentos}

Após a obtenção do fluxo de caixa contendo as entradas e saídas monetárias ao longo do horizonte de planejamento, utilizaram-se ferramentas da engenharia econômica para a avaliação da rentabilidade do manejo. Dentre os vários métodos, foram usados o Valor Presente Líquido (VPL) e a Taxa Interna de Retorno (TIR). De acordo com Rezende; Oliveira (2001), o VPL e a TIR podem ser expressos pelas seguintes fórmulas:

$$
V P L=\sum_{j=0}^{n} R j(1+i)^{-j}-\sum_{J=0}^{n} C j(1+i)^{-j}
$$

Em que: $\mathrm{Rj}=$ Receitas do período de tempo $\mathrm{j}$ considerado.

$\mathrm{C} \mathrm{j}=$ Custos do período de tempo $\mathrm{j}$ considerado.

$\mathrm{n}=$ Duração do projeto em anos ou em número de períodos de tempo.

$\mathrm{i}=$ Taxa anual de juro, expressa de forma decimal.

$$
T I R=\sum_{j=0}^{n} R j(1+i)^{-j}-\sum_{j=0}^{n} C j(1+i)^{-j}=0
$$

Em que: $\mathrm{Rj}=$ Receitas do período de tempo $\mathrm{j}$ considerado.

$\mathrm{j}=$ Custos do período de tempo $\mathrm{j}$ considerado.

$\mathrm{n}=$ Duração do projeto em anos ou em número de períodos de tempo.

\section{Taxa Mínima de Atratividade (TMA)}

De acordo com Lima Jr., Rezende; Oliveira (1997), as taxas reais de juros para analisar projetos florestais no Brasil situam-se entre 6 a 12\% ao ano. Para este estudo, a TMA utilizada para descontar os valores do fluxo de caixa foi de $12 \%$ ao ano, baseado em Timofeiczyk (2004).

\section{Rentabilidade com um ciclo de produção}

Para determinar a rentabilidade com um ciclo de produção, foram utilizados dois cenários de análise. No cenário A, foi considerada a produção atual da empresa, que é de $12 \mathrm{~m}^{3} / \mathrm{ha}$, e o efeito da 
implantação dos tratos silviculturais na rentabilidade, quando comparado a situações em que ela não é executada.

Estudos em andamento na empresa apontam para a possibilidade de redução dos desperdícios de madeira no primeiro ciclo nas operações de exploração. No cenário $B$, considerou-se a elevação da produtividade de $12 \mathrm{~m}^{3} /$ ha para $15 \mathrm{~m}^{3} /$ ha no primeiro ciclo. Ainda nesse cenário, foi analisado o impacto da implantação dos tratos silviculturais na rentabilidade, quando comparado a situações em que ela não é realizada.

\section{Rentabilidade com dois ciclos de produção}

Para determinar a rentabilidade com dois ciclos de produção, foram considerados três cenários. No cenário $C$, a produção no primeiro e no segundo ciclo foi de $12 \mathrm{~m}^{3} / \mathrm{ha}$, sem a inclusão de tratos silviculturais. No cenário $\mathrm{D}$, considerou-se que o crescimento das árvores aumentaria por meio da implantação dos tratos silviculturais. Amaral et al. (1998) afirmam que o acréscimo de volume a ser explorado no segundo ciclo, em função dos tratos silviculturais, é de 16\%. Determinou-se a rentabilidade considerando $12 \mathrm{~m}^{3} /$ ha no primeiro ciclo e $15 \mathrm{~m}^{3} /$ ha no segundo, em função da implantação dos tratos silviculturais, com e sem limpeza de estradas secundárias e esplanadas.

No cenário E, considerou-se de $15 \mathrm{~m}^{3} /$ ha no primeiro ciclo em função da redução do desperdício nas operações de exploração. No segundo ciclo, foi considerada a produtividade de $18 \mathrm{~m}^{3} /$ ha em função da redução do desperdício das operações de exploração, aliada à influência dos tratos silviculturais executadas no primeiro ciclo de produção. Nesse cenário, a rentabilidade foi calculada também com e sem limpeza de estradas secundárias e esplanadas.

\section{Investimento em terra} situações:

Em relação ao investimento em terra, nos cenários já descritos foram consideradas duas

a) Investimento ocorrendo no início do fluxo de caixa.

b) Sem investimento em terra.

\section{Análise de sensibilidade}

Conforme Hildebrand (1995), no setor florestal poucos são os trabalhos publicados que envolvem custos de produção. Essa escassez de trabalhos dificulta realizar comparações de custos. Ressalte-se também que há escassez de dados sobre série histórica de preços, constituindo uma limitação dessa análise.

Segundo Kassai et al. (2000), a análise de sensibilidade é utilizada normalmente em situações em que não há informações sobre a distribuição de probabilidades. A finalidade dessa análise é auxiliar as tomadas de decisão ao se examinar eventuais alterações de valores, como a TIR e o VPL, produzidos por variações nos valores dos parâmetros componentes do fluxo de caixa.

Além da análise de cenários, optou-se também pela análise de sensibilidade envolvendo preços e custos de produção, para melhor visualizar os impactos dessas variáveis. Por estar ao alcance da empresa, essa análise foi realizada no cenário E, com produção de $15 \mathrm{~m}^{3} /$ ha no primeiro ciclo e $18 \mathrm{~m}^{3} / \mathrm{ha} \mathrm{no}$ segundo ciclo.

A análise de sensibilidade foi realizada com os preços das toras e os custos de produção, com variações reais compreendidas entre $-30 \%$ e $+30 \%$, com intervalos de $10 \%$. Admite-se como premissa que todos os preços e custos subirão na mesma proporção, portanto, sujeitos à mesma variação. Nesse caso, não é necessário levar em consideração a inflação (CASAROTTO; KOPITTKE, 1994).

\section{RESULTADOS}

\section{Rentabilidade com um ciclo de produção Cenário A}

Os trabalhos existentes sobre economicidade do manejo, além de serem realizados em escala piloto, portanto distantes da realidade das empresas, consideram apenas um ciclo de produção. Barreto et al. (1998) recomendam que os estudos sobre o manejo sejam realizados com mais de um ciclo, o que torna os resultados mais próximos da realidade. 
Ao se analisar a rentabilidade do manejo florestal considerando apenas um ciclo, estar-se-á desconsiderando os custos e receitas do segundo ciclo. O primeiro ciclo deve ser considerado como implantação do sistema de manejo sustentado, que será obtido a partir do segundo ciclo.

O objetivo do manejo é manter a floresta para as gerações futuras. De acordo com Yared (1992), o sistema de manejo florestal aplicado à produção madeireira envolve um conjunto de atividades relacionadas com os processos de extração da madeira, com o monitoramento da floresta e com os tratos silviculturais aplicados para garantir futuras safras.

É um conjunto de atividades realizadas antes, durante e após a extração da madeira, visando garantir colheitas no futuro, bem como reduzir os impactos ambientais por ocasião da extração da madeira. Dentro desse conceito, os tratos silviculturais objetivam repor o estoque de madeira retirado entre os ciclos de corte. A inclusão desses tratos em um único ciclo compromete o resultado final, pois são gerados custos, sem a inclusão da receita gerada por aqueles custos adicionais.

$\mathrm{Na}$ tabela 2 são apresentados a TIR e o VPL do cenário A, com o volume de $12 \mathrm{~m}^{3} / \mathrm{ha}$ de madeira atualmente comercializado pela empresa, com e sem tratos silviculturais, considerando investimento em terras no início do período de análise (145.000 ha) e sem considerar o investimento nesse recurso de produção. A inclusão dos tratos silviculturais diminuiu a TIR e o VPL, já que houve aumento do custo de produção, sem a devida análise das receitas futuras que ocorreram após o horizonte de planejamento. Outro fator importante a ser considerado na análise é o impacto do custo de aquisição de terras no resultado financeiro. Em estudos realizados por Souza (2002), o manejo em florestas privadas revelou-se não rentável, apresentando VPL negativo para qualquer taxa de desconto utilizada, principalmente em função do peso que o custo de aquisição da terra tem na análise.

Com investimento em terras e com realização dos tratos silviculturais, a TIR e o VPL apresentaram os mais baixos valores, com $0,45 \%$ e - R $\$ 41.294 .206$, respectivamente (Tabela 2). Esse valor do VPL é em função do desconto realizado no fluxo de caixa, pois quanto mais distantes no tempo se encontram as receitas e despesas, menores serão os seus impactos no presente.

A terra, que é um bem não depreciável, representa saída de caixa no momento presente quando considerado um único desembolso para a sua aquisição. No momento final de análise, considera-se entrada de caixa com o mesmo valor inicial, desde que não ocorra apreciação no seu valor. Essa diferença temporal entre a saída de caixa no presente e entrada no futuro é responsável por esse impacto no VPL. Caso a terra dobre o seu valor no final do horizonte de planejamento, a TIR e o VPL aumentariam para $5,40 \%$ e -R\$ 10.520.102, valores bem distantes ainda do desejado, se considerado TMA de $12 \%$ ao ano.

Ao se desconsiderar o valor da terra, houve uma melhora significativa nos indicadores econômicos. Mesmo com baixa produtividade, ao não se considerarem os tratos silviculturais, o VPL tornou-se positivo e o valor da TIR ficou acima de 12\%. A inclusão dos tratos silviculturais promoveu a redução da TIR para 10,21\% e do VPL para -R \$353.020, fato esse decorrente da inclusão dos custos sem a devida consideração das receitas que seriam geradas em função desses tratos (Tabela 2).

Tabela 2. Rentabilidade com um ciclo de produção e duas situações de investimento em terra, com e sem tratos silviculturais, e volume de $12 \mathrm{~m}^{3} /$ ha.

Table 2. Profitability with one production cycle and two situations of investment in land, with and without silviculture treatments, and volume of $12 \mathrm{~m}^{3} / \mathrm{ha}$.

\begin{tabular}{lcc}
\hline Com investimento em terra & TIR (\%) & VPL (R\$) \\
\hline $12 \mathrm{~m}^{3} /$ ha (SAS) & 0,67 & -40.724 .137 \\
$12 \mathrm{~m}^{3} /$ ha (CAS) & 0,45 & -41.294 .206 \\
\hline Sem investimento em terra & TIR (\%) & VPL (R\$) \\
\hline $12 \mathrm{~m}^{3} /$ ha (SAS) & 12,99 & 217.049 \\
$12 \mathrm{~m}^{3} /$ ha (CAS) & 10,21 & -353.020 \\
\hline
\end{tabular}

Fonte: Timofeiczyk (2004).

SAS: sem tratos silviculturais; CAS: com tratos silviculturais.

\section{Cenário B}

Estudos em andamento na empresa apontam para a possibilidade de redução dos desperdícios de madeira no primeiro ciclo. A tabela 3 contém a TIR e o VPL do cenário $\mathrm{B}$, com o volume de $15 \mathrm{~m}^{3} / \mathrm{ha}$ a 
ser obtido com essa redução, considerando investimento da terra no início do período de análise, e sem considerar os investimentos em terras.

Considerando aquisição de terras e os tratos silviculturais, os indicadores continuaram apresentando os mais baixos valores, porém superiores ao cenário anterior, com TIR de 1,51\% e VPL de $-\mathrm{R} \$$ 37.653.432. Com a redução do desperdício, houve um grande aumento nos valores ao se desconsiderar o valor da terra, mesmo incluindo os tratos silviculturais. A TIR e o VPL atingiram os valores de $25,88 \%$ e R $\$ 3.287 .754$, respectivamente, sendo superiores aos encontrados para o volume de $12 \mathrm{~m}^{3} /$ ha (Tabela 3 ).

Tabela 3. Rentabilidade com um ciclo de produção e duas situações de investimento em terra, com e sem tratos silviculturais, e volume de $15 \mathrm{~m}^{3} / \mathrm{ha}$.

Table 3. Profitability with one production cycle and two situations of investment in land, with and without silviculture treatments, and volume of $15 \mathrm{~m}^{3} / \mathrm{ha}$.

\begin{tabular}{lll}
\hline Com investimento em terra & TIR (\%) & VPL (R\$) \\
\hline $15 \mathrm{~m}^{3} /$ ha (SAS) & 1,71 & -37.083 .362 \\
$15 \mathrm{~m}^{3} /$ ha (CAS) & 1,51 & -37.653 .432 \\
\hline Sem investimento em terra & TIR (\%) & VPL (R\$) \\
\hline $15 \mathrm{~m}^{3} /$ ha (SAS) & 27,47 & 3.857 .823 \\
$15 \mathrm{~m}^{3} /$ ha (CAS) & 25,88 & 3.287 .754 \\
\hline
\end{tabular}

Fonte: Timofeiczyk (2004).

SAS: sem tratos silviculturais; CAS: com tratos silviculturais.

\section{Rentabilidade com dois ciclos de produção}

Cenário C

Uma das grandes dúvidas existentes é até que ponto os custos decorrentes dos tratos silviculturais serão compensados pelo incremento que se obterá da floresta e, conseqüentemente, pelas receitas adicionais que serão geradas em função dessa prática. Outra dúvida refere-se à inclusão na atividade pós-exploratória da limpeza de estradas secundárias e esplanadas, realizada com uma roçadeira tracionada, acoplada a um trator de pneu $4 \times 4$.

Tal operação é realizada após cinco anos da extração da madeira, implicando na inserção de uma nova unidade de produção no cronograma operacional dentro desse prazo. Ao iniciar o segundo ciclo, o custo com essa operação não sofreu mais alteração, em função de não ter havido introdução de novas áreas no cronograma operacional. Entretanto, essa prática eliminou algumas operações da atividade exploratória, como a demarcação e abertura de estradas secundárias e esplanadas, o que levou à redução do custo total de produção no segundo ciclo.

Por outro lado, a exclusão dessa operação da atividade pós-exploratória torna necessária a execução das operações da atividade exploratória que seriam eliminadas. Isso se deve em razão da regeneração da floresta nas estradas secundárias e esplanadas, exigindo a utilização de tratores de esteiras, com custo maior do que o trator de pneu. A regeneração existente por ocasião do início do segundo ciclo não é intensa como na primeira intervenção, permitindo um maior rendimento do trator de esteira, com o custo menor que o verificado no primeiro ciclo.

A tabela 4 mostra a TIR e o VPL do cenário $\mathrm{C}$, com $12 \mathrm{~m}^{3} /$ ha e sem considerar os tratos silviculturais. Verificou-se que a TIR e o VPL apresentaram valores maiores quando foi considerada a limpeza de estradas secundárias e esplanadas, independentemente se ocorreu ou não investimento em terra. Isso indica que a redução dos custos da atividade exploratória no segundo ciclo teve influência maior nos resultados do que o aumento dos custos da atividade pós-exploratória, em função da introdução da limpeza das estradas secundárias e esplanadas.

Comparando os resultados da tabela 4, que considerou dois ciclos de produção, com a tabela 2, onde foi considerado apenas um ciclo, apesar de ambos terem o mesmo volume comercializado (12 $\mathrm{m}^{3} / \mathrm{ha}$ ), verificou-se que a TIR com dois ciclos foi superior em qualquer situação. Com um ciclo de produção, a TIR apresentou o seu maior valor (12,99\%) quando a aquisição em terra e os tratos silviculturais não foram considerados. Já com dois ciclos e não considerando o valor da terra, o maior valor da TIR foi de 13,63\%, quando a limpeza de estradas secundárias e esplanadas foi considerada. 
Tabela 4. Rentabilidade com dois ciclos de produção e duas situações de investimento em terra, sem tratos silviculturais, com e sem limpeza de estradas secundárias e esplanadas e volume de 12 $\mathrm{m}^{3} / \mathrm{ha}$.

Table 4. Profitability with two production cycles and two situations of investment in land, without silviculture treatments, with and without cleanness of roads and trails and volume of $12 \mathrm{~m} / \mathrm{ha}$.

\begin{tabular}{lcc}
\hline Com investimento em terra & TIR (\%) & VPL (R\$) \\
\hline $12 \mathrm{~m}^{3} /$ ha (SLE) & 0,97 & -42.910 .892 \\
$12 \mathrm{~m}^{3} /$ ha (CLE) & 1,18 & -42.890 .458 \\
\hline Sem investimento em terra & TIR (\%) & VPL (R\$) \\
\hline $12 \mathrm{~m}^{3} /$ ha (SLE) & 13,66 & 438.590 \\
$12 \mathrm{~m}^{3} /$ ha (CLE) & 13,63 & 459.024 \\
\hline
\end{tabular}

Fonte: Timofeiczyk (2004).

SLE: sem limpeza de estradas secundárias e esplanadas; CLE: com limpeza de estradas secundárias e esplanadas.

Entretanto, o VPL apresentou menores valores ao serem analisados dois ciclos de produção, com o valor da terra sendo inclú́do na análise. Com um ciclo, a entrada no fluxo de caixa do valor da terra ocorreu no final do $25^{\circ}$ ano, enquanto que em dois ciclos o retorno aconteceu no final do $50^{\circ}$ ano.

A diferença temporal ocasionou esse impacto no VPL. Quando o valor da terra foi desconsiderado, os maiores valores do VPL ocorreram com dois ciclos de produção, como é possível verificar nas tabelas 2 e 4 . Considerando um ciclo de produção e sem tratos silviculturais, o VPL foi de R\$ 217.049. Já com dois ciclos, e com limpeza de estradas secundárias e esplanadas, o VPL foi de R\$ 459.024. Esses resultados corroboram a afirmação de alguns autores, que salientam a necessidade de considerar mais de um ciclo na análise econômica do manejo nas florestas tropicais.

\section{Cenário D}

Com a implantação dos tratos silviculturais, estimou-se que o volume no segundo ciclo foi de 15 $\mathrm{m}^{3} /$ ha, desde que não sejam realizados esforços visando à redução de desperdícios. Ocorrendo o investimento em terra, verificou-se que, mesmo com a implantação dos tratos silviculturais, a TIR aumentou o seu valor em relação ao cenário anterior. Adicionando, além dos tratos silviculturais, a limpeza de estradas secundárias e esplanadas, a TIR elevou-se ainda mais, porém continuou baixa quando comparada à TMA (Tabela 5).

Tabela 5. Rentabilidade com $12 \mathrm{~m}^{3} /$ ha no primeiro ciclo e $15 \mathrm{~m}^{3} /$ ha no segundo ciclo e duas situações de investimento em terra, com tratos silviculturais, com e sem limpeza de estradas secundárias e esplanadas.

Table 5. Profitability with $12 \mathrm{~m}^{3} /$ ha in the first cycle and $15 \mathrm{~m}^{3} / \mathrm{ha}$ in the second cycle and two situations of investment in land, with silviculture treatments, with and without cleanness of roads and trails.

\begin{tabular}{lcc}
\hline Com investimento em terra & TIR (\%) & VPL (R\$) \\
\hline $12 \mathrm{~m}^{3} /$ ha e $15 \mathrm{~m}^{3} /$ ha (SLE) & $1,34 \%$ & -43.139 .242 \\
$12 \mathrm{~m}^{3} /$ ha e $15 \mathrm{~m}^{3} /$ ha (CLE) & $1,53 \%$ & -43.118 .808 \\
\hline Sem investimento em terra & TIR (\%) & VPL (R\$) \\
\hline $12 \mathrm{~m}^{3} /$ ha e $15 \mathrm{~m}^{3} /$ ha (SLE) & $12,68 \%$ & 210.240 \\
$12 \mathrm{~m}^{3} /$ ha e $15 \mathrm{~m}^{3} /$ ha (CLE) & $12,70 \%$ & 230.673 \\
\hline
\end{tabular}

Fonte: Timofeiczyk (2004).

SLE: sem limpeza de estradas secundárias e esplanadas; CLE: com limpeza de estradas secundárias e esplanadas.

A implantação dos tratos silviculturais promoveu a redução dos custos médios de produção no segundo ciclo. Os custos fixos e parte dos custos variáveis (atividades pré e pós-exploratórias) foram distribuídos em uma quantidade maior de toras, aumentando a receita líquida. $\mathrm{O}$ aumento na receita líquida total no segundo ciclo foi proporcionalmente maior que o aumento no custo total no primeiro ciclo. Como resultado, a TIR apresentou-se ligeiramente maior quando comparada ao cenário em que tais tratos não foram realizados. 
A não realização da limpeza de estradas secundária e esplanadas resultou em receitas líquidas maiores no primeiro ciclo e menores no segundo ciclo, em razão da execução das operações contidas na atividade exploratória. Verificou-se pela TIR e VPL que o aumento da receita líquida no primeiro ciclo não compensou a redução da receita no segundo ciclo (Tabela 5). Quando o custo de aquisição em terra foi desconsiderado, a TIR apresentou-se maior com a execução de limpeza de estradas secundárias e esplanadas. Nessa situação, o VPL foi positivo, com taxa de desconto de 12\% (Tabela 5).

\section{Cenário E}

A redução do desperdício, além de ser uma realidade e um procedimento fundamental na racionalização do uso dos recursos, tem fácil aceitação por trazer resultados favoráveis, tanto aos interesses empresariais quanto aos interesses do meio ambiente. Para tanto, são necessárias adoções de novas técnicas nas operações de exploração da madeira. Detalhes como a redução na altura do corte e melhor aproveitamento de madeira com valor comercial na copa, aliados à eliminação de toras não encontradas pelo operador do trator de arraste, podem aumentar o volume de $12 \mathrm{~m}^{3} /$ ha para $15 \mathrm{~m}^{3} / \mathrm{ha}$ a partir do primeiro ciclo. Esse aumento de produção em função da redução do desperdício nas operações de exploração, conjugado com a implantação dos tratos silviculturais e o conseqüente aumento do incremento da floresta remanescente, podem aumentar o volume de $15 \mathrm{~m}^{3} /$ ha para $18 \mathrm{~m}^{3} /$ ha no segundo ciclo de produção.

Considerando os custos com investimento em terra, quando comparada aos cenários anteriores, a TIR apresentou elevação no seu valor, enquanto o VPL continuou negativo. Esse quadro mostra que, apesar de ter havido uma melhora em relação aos cenários anteriores, ainda continua muito abaixo da TMA de $12 \%$ ao ano adotada neste trabalho (Tabela 6). Quando o investimento em terra foi desconsiderado, ocorreu uma elevação significativa na TIR e no VPL, principalmente quando se considerou a limpeza de estradas secundárias e esplanadas. Nesse caso, o VPL foi de R $\$ 4.274 .460$, e a TIR de 26,23\% (Tabela 6).

Tabela 6. Rentabilidade com $15 \mathrm{~m}^{3} /$ ha no primeiro ciclo e $18 \mathrm{~m}^{3} /$ ha no segundo ciclo e duas situações de investimento em terra, com tratos silviculturais, com e sem limpeza de estradas secundárias e esplanadas.

Table 6. Profitability with $15 \mathrm{~m}^{3} /$ ha in the first cycle and $18 \mathrm{~m}^{3} /$ ha in the second cycle and two situations of investment in land, with silviculture treatments, with and without cleanness of roads and trails.

\begin{tabular}{lcc}
\hline Com investimento em terra & TIR (\%) & VPL (R\$) \\
\hline $15 \mathrm{~m}^{3} /$ ha e $18 \mathrm{~m}^{3} /$ ha (SLE) & 2,31 & -39.267 .784 \\
$15 \mathrm{~m}^{3} /$ ha e $18 \mathrm{~m}^{3} /$ ha (CLE) & 2,52 & -39.208 .798 \\
\hline Sem investimento em terra & TIR (\%) & VPL (R\$) \\
\hline $15 \mathrm{~m}^{3} /$ ha e $18 \mathrm{~m}^{3} /$ ha (SLE) & 26,20 & 4.081 .699 \\
$15 \mathrm{~m}^{3} /$ ha e $18 \mathrm{~m}^{3} /$ ha (CLE) & 26,23 & 4.274 .460 \\
\hline
\end{tabular}

Fonte: Timofeiczyk (2004)

SLE: sem limpeza de estradas secundária e esplanadas; CLE; com limpeza de estradas secundária e esplanadas.

\section{Análise de sensibilidade}

Considerando investimento em terra

O preço de comercialização das toras apresentou uma relação diretamente proporcional com os métodos de análise de rentabilidade, em que uma elevação ou redução nos preços contribuiu, respectivamente, para a elevação ou redução da TIR e VPL (Figura 1). Por outro lado, os custos de produção apresentaram uma relação inversamente proporcional com a rentabilidade, tendo em vista que uma elevação ou redução dos custos possibilitou, respectivamente, a redução ou elevação da TIR e VPL.

Dentro do intervalo considerado, verificou-se que a TIR e o VPL foram mais sensíveis às variações nos preços das toras do que nos custos de produção (Tabela 7). Com redução real de $30 \%$ nos preços de comercialização, inexistiu solução para a TIR e o VPL apresentou o menor valor. Aumentos reais de $30 \%$ no preço das toras elevaram a TIR em $2,85 \%$, correspondendo a um aumento relativo de $113,10 \%$. Nessa mesma situação, o VPL reduziu seu valor negativo em R\$ 11.856.723, correspondendo a um aumento de $30,24 \%$. 
Outro fator que elevou a rentabilidade foi a redução nos custos de produção. Decréscimos reais de 30\% aumentaram a TIR em 2,16\%, significando um aumento de 85,71\%. Nessa situação, o VPL aumentou em R $\$ 8.429 .173$, correspondendo a um aumento de $24,06 \%$, valor esse inferior quando houve aumentos reais na mesma proporção nos preços (Tabela 7).

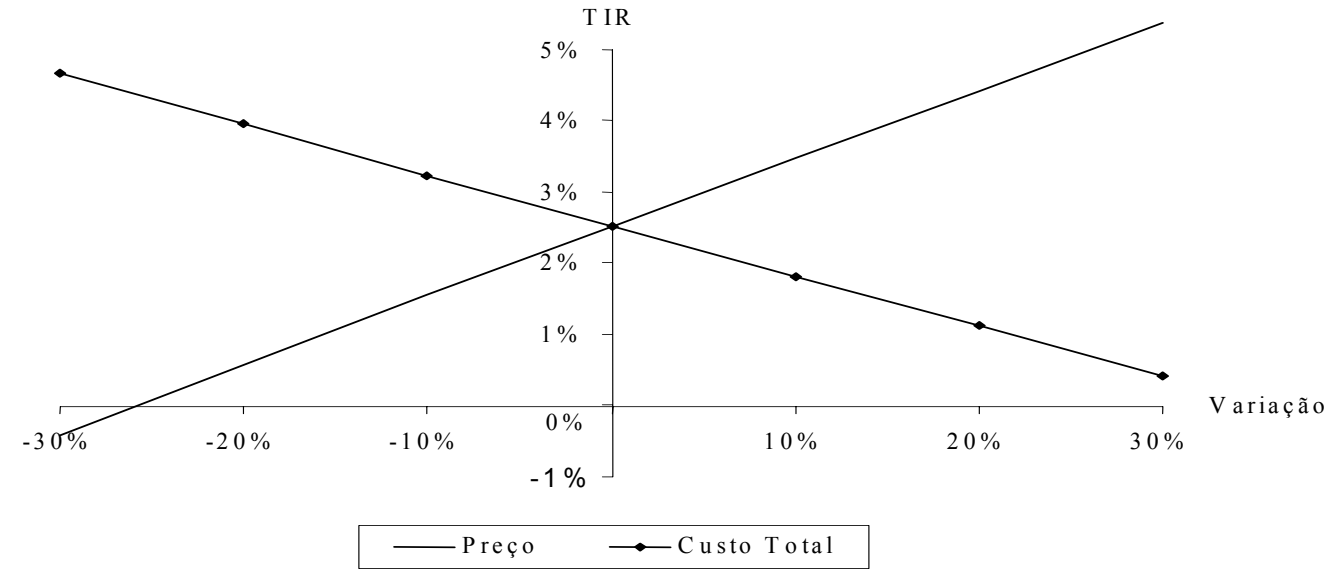

Fonte: Timofeiczyk (2004).

Figura 1. Análise de sensibilidade da TIR a variações nos preços das toras e nos custos de produção, considerando o valor da terra.

Figure 1. Sensibility analysis of TIR and the variations on the logs prices and production cost considering land value.

Tabela 7. Análise de sensibilidade da TIR e do VPL a variações nos custos de produção e no preço de venda das toras, considerando o valor da terra.

Table 7. Sensibility analysis of TIR and of VPL with variations on the production costs and logs sell prices considering land value.

\begin{tabular}{lcccc}
\hline Itens & \multicolumn{2}{c}{ Preço das toras } & \multicolumn{2}{c}{ Custo de produção } \\
\hline Variação & TIR (\%) & VPL (R\$) & TIR (\%) & VPL (R\$) \\
\hline$-30 \%$ & - & -51.065 .520 & 4,68 & -29.776 .625 \\
$-20 \%$ & 0,57 & -47.113 .279 & 3,95 & -32.920 .683 \\
$-10 \%$ & 1,55 & -43.161 .079 & 3,23 & -36.064 .740 \\
$0 \%$ & 2,52 & -39.208 .798 & 2,52 & -39.208 .798 \\
$+10 \%$ & 3,48 & -35.256 .557 & 1,82 & -42.352 .855 \\
$+20 \%$ & 4,42 & -31.304 .316 & 1,12 & -45.496 .913 \\
$+30 \%$ & 5,37 & -27.352 .075 & 0,43 & -48.640 .970 \\
\hline
\end{tabular}

Fonte: Timofeiczyk (2004).

A tabela 8 contém os resultados da análise de sensibilidade realizada com os preços das toras e os custos de produção, com variações reais entre $-30 \%$ e $+30 \%$. Na melhor hipótese possível, com aumento real de $30 \%$ nos preços e redução real de $30 \%$ nos custos, a TIR foi de $7,58 \%$.

Apesar da TIR e do VPL apresentarem uma sensibilidade maior a variações nos preços das toras quando comparada aos custos de produção, não se vislumbram aumentos reais nos preços de madeira de floresta tropicais. Parte da madeira extraída na Amazônia provém de sistemas de manejo nãosustentáveis, ocasionando a baixa competitividade da madeira oriunda de manejo florestal sustentável. De acordo com Souza (2002), o baixo valor da madeira é decorrente da abundância da oferta no mercado, de origem insustentável e/ou ilegal. 
Tabela 8. Análise de sensibilidade da TIR com variações no preço das toras e no custo total de produção, considerando o valor da terra.

Table 8. Sensibility analysis of TIR with variations on the logs prices and total production cost, considering land value.

\begin{tabular}{lccccccc}
\hline \multirow{2}{*}{ Custo } & \multicolumn{7}{c}{ Preç } \\
\cline { 2 - 8 } & $\mathbf{+ 3 0 \%}$ & $\mathbf{+ 2 0 \%}$ & $\mathbf{+ 1 0 \%}$ & $\mathbf{0 \%}$ & $\mathbf{- 1 0 \%}$ & $\mathbf{- 2 0 \%}$ & $\mathbf{- 3 0 \%}$ \\
\hline$+30 \%$ & 3,26 & 2,33 & 1,39 & 0,43 & - & - & - \\
$+20 \%$ & 3,95 & 3,02 & 2,07 & 1,12 & 0,15 & - & - \\
$+10 \%$ & 4,66 & 3,72 & 2,77 & 1,82 & 0,85 & - & - \\
$0 \%$ & 5,37 & 4,42 & 3,48 & 2,52 & 1,55 & 0,57 & - \\
$-10 \%$ & 6,10 & 5,14 & 4,19 & 3,23 & 2,26 & 1,28 & 0,29 \\
$-20 \%$ & 6,83 & 5,87 & 4,91 & 3,95 & 2,98 & 2,00 & 1,01 \\
$-30 \%$ & 7,58 & 6,61 & 5,65 & 4,68 & 3,71 & 2,73 & 1,73 \\
\hline Fonte: Timofeiczyk (2004)
\end{tabular}

Segundo Siqueira (1999), as crescentes restrições ao uso de madeira nativa e principalmente o alto custo do transporte para os grandes centros consumidores favorece a produção de serrados com base de Eucalyptus. Esse gênero terá uma penetração no mercado via substituição de nativas e possivelmente para cobrir a limitação no suprimento de madeira de Pinus. Ainda segundo o mesmo autor, as madeiras nativas destinadas para lâminas e compensados também poderão ser substituídas pelo Eucalyptus. Esses fatos inibem aumentos reais de preços para as toras de baixo valor comercial de florestas tropicais.

Angelo (1998) afirma que a substituição de madeiras tropicais pelas coníferas é uma hipótese a ser considerada. Segundo ainda o mesmo autor, estudos demonstraram a tendência de substituição da madeira tropical - hardwoods - pelas softwoods, com elasticidade preço-cruzada positiva.

Não considerando investimento em terra

A exclusão do valor do investimento em terra aumentou consideravelmente a rentabilidade, evidenciando o grande impacto que essa variável apresentou na análise econômica (Figura 2). Outro fato evidente da importância do investimento em terra é o formato das curvas da TIR. Comparando-se as figuras 1 e 2, observa-se que, ao se desconsiderar investimento em terra, as curvas de sensibilidade dos preços e dos custos tornaram-se nitidamente côncavas na extremidade inferior, evidenciando uma tendência exponencial. Esse fato ocorre em razão do valor da terra ser a principal variável dos investimentos.

Os resultados da análise de sensibilidade encontram-se na tabela 9. Nesse intervalo, a rentabilidade continuou sendo mais sensível às variações reais nos preços das toras do que nos custos de produção. O VPL e a TIR tiveram a sensibilidade aumentada em relação às duas variáveis (preço das toras e custos de produção), quando foi retirado da análise o valor da terra.

Havendo reduções da ordem de $30 \%$ nos preços de comercialização das toras, a TIR não apresentou solução e o VPL atingiu o menor valor. Aumentos reais de 30\% no preço das toras elevaram a TIR em 40,6\%, correspondendo a um aumento de $155,79 \%$. Nessa situação, o VPL aumentou seu valor em R\$11.856.723, significando aumento de 286,35\% (Tabela 9).

Verificou-se também que decréscimos reais de $30 \%$ nos custos de produção elevaram a TIR em 34,91\%, correspondendo a um aumento de 133,96\%. Nessa mesma hipótese, o VPL elevou seu valor em R\$ 9.432.173, correspondendo a um incremento de 227,79\%. Por outro lado, aumentos de $30 \%$ nos custos de produção diminuíram a TIR em 90,98\% e o VPL tornou-se negativo (Tabela 9).

As maiores alterações relativas ocorreram no VPL em razão de ele ser muito sensível ao valor da terra. Com a não inclusão do valor da terra nos custos com investimentos, estar-se-á retirando da análise uma variável que ocasiona um grande impacto no momento presente. Isso ocorre em função do seu desembolso ser computado como saída de caixa no momento inicial da análise (momento presente) e o retorno se dar no final do horizonte de planejamento. 


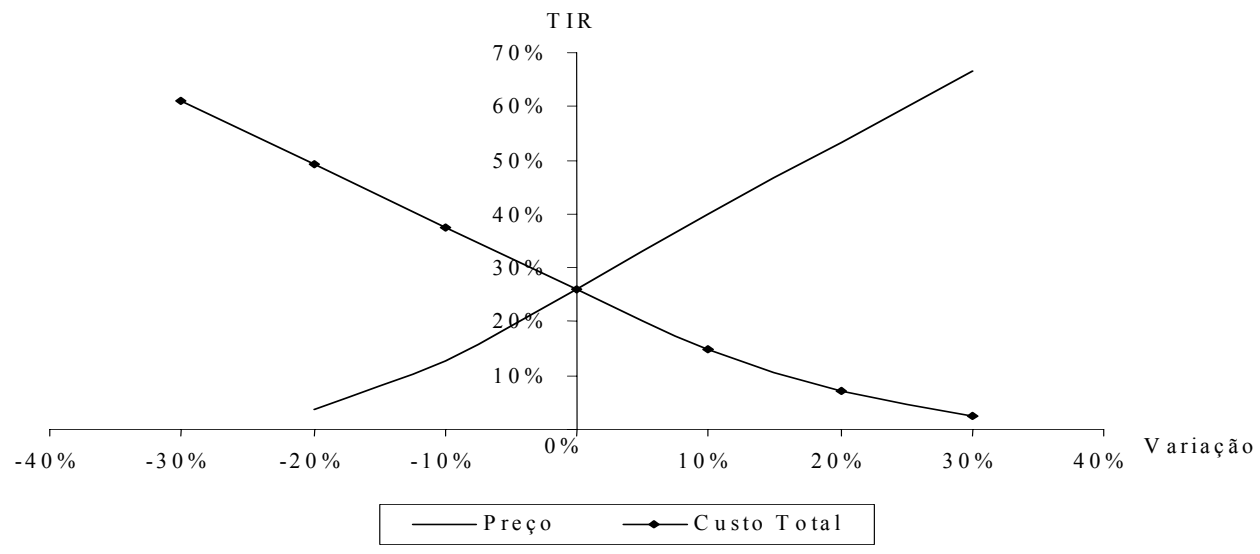

Fonte: Timofeiczyk (2004).

Figura 2. Análise de sensibilidade da TIR a variações nos preços das toras e dos custos de produção, não considerando o valor da terra.

Figure 2. Sensibility analysis of TIR and variations on the logs price and production costs, don't considering land value.

Tabela 9. Análise de sensibilidade da TIR e do VPL a variações nos custos de produção e no preço de vendas das toras, não considerando o valor da terra.

Table 9. Sensibility analysis of TIR and of VPL with variations on the production costs and logs sell price, don't considering land value.

\begin{tabular}{lcccc}
\hline Itens & \multicolumn{2}{c}{ Preço das toras } & \multicolumn{2}{c}{ Custo de produção } \\
\hline Variação & TIR (\%) & VPL (R\$) & TIR (\%) & VPL (R\$) \\
\hline$-30 \%$ & - & -7.716 .038 & 60,97 & 13.572 .856 \\
$-20 \%$ & 3,68 & -3.763 .797 & 49,19 & 10.428 .798 \\
$-10 \%$ & 12,55 & 188.442 & 37,59 & 7.284 .741 \\
$0 \%$ & 26,06 & 4.140 .683 & 26,06 & 4.140 .683 \\
$+10 \%$ & 39,92 & 8.092 .924 & 14,99 & 996.626 \\
$+20 \%$ & 53,40 & 12.045 .165 & 7,06 & -2.147 .431 \\
$+30 \%$ & 66,66 & 15.997 .406 & 2,35 & -5.291 .488 \\
\hline
\end{tabular}

Fonte: Timofeiczyk (2004).

A tabela 10 contém os resultados da análise de sensibilidade realizada com os preços das toras e os custos de produção, com variações reais entre $-30 \%$ e $+30 \%$. Verificou-se que, mesmo não considerando o investimento em terra, houve determinadas situações em que a TIR não apresentou solução. No cenário mais positivo, em que há aumentos reais de $30 \%$ no preço das toras, aliado às reduções de $30 \%$ nos custos, a TIR atingiu o excepcional valor de 102,22\%. Apesar da impossibilidade de se calcular a probabilidade de ocorrência desse evento, sabe-se que é praticamente impossível ele ser concretizado.

Os resultados obtidos neste trabalho demonstram a baixa rentabilidade do manejo em escala empresarial, quando executado em florestas tropicais, considerando o valor da terra. Alguns fatores contribuem para essa realidade, podendo-se citar, entre outros, a maior rentabilidade econômica da extração ilegal dos recursos florestais, que, como conseqüência, pressiona os preços para baixo em função do aumento da oferta de madeiras no mercado.

Estudos realizados por Ângelo; Prado; Brasil (2004) mostraram que o baixo preço da madeira estimula a conversão de áreas florestais para outros usos, provocando o desmatamento e influenciando significativamente as quantidades ofertadas. Já a produção oriunda de área de floresta manejada não contribui significativamente para a oferta de madeira, com elasticidade de substituição entre essas fontes 
de oferta sendo significativa e positiva, o que demonstra que o manejo florestal compete com o desmatamento na oferta de madeiras tropicais.

Tabela 10. Análise de sensibilidade da TIR com variações no preço das toras e no custo total de produção, não considerando o valor da terra.

Table 10. Sensibility analysis of TIR with variations on the logs price and total production cost, don't considering land value.

\begin{tabular}{lccccccc}
\hline \multirow{2}{*}{ Custo } & \multicolumn{7}{c}{ Preço } \\
\cline { 2 - 7 } & $\mathbf{+ 3 0 \%}$ & $\mathbf{+ 2 0 \%}$ & $\mathbf{+ 1 0 \%}$ & $\mathbf{0 \%}$ & $\mathbf{- 1 0 \%}$ & $\mathbf{- 2 0 \%}$ & $\mathbf{- 3 0 \%}$ \\
\hline$+30 \%$ & 33,39 & 20,03 & 9,60 & 4,86 & 2,18 & 0,22 & - \\
$+20 \%$ & 44,34 & 31,03 & 17,55 & 8,22 & 4,08 & 1,59 & - \\
$+10 \%$ & 55,40 & 42,17 & 28,58 & 15,14 & 7,01 & 3,35 & 1,03 \\
$0 \%$ & 66,66 & 53,40 & 39,92 & 26,06 & 12,88 & 5,94 & 2,66 \\
$-10 \%$ & 78,18 & 64,82 & 51,33 & 37,59 & 23,45 & 10,85 & 4,97 \\
$-20 \%$ & 90,02 & 76,52 & 62,93 & 49,19 & 35,18 & 20,77 & 9,09 \\
$-30 \%$ & 102,22 & 88,53 & 74,79 & 60,97 & 49,97 & 32,67 & 18,05 \\
\hline
\end{tabular}

Fonte: Timofeiczyk (2004).

A tabela 11 contém as variações reais de preços necessárias para que seja alcançada TIR de 6\% e $12 \%$ ao ano, considerando investimento em terra e os cenários com dois ciclos de produção. Nos três cenários houve a necessidade de aumento real de preço para que a TIR estabelecida seja alcançada. No cenário D, para obter TIR de $12 \%$ ao ano, necessita-se de aumento no nível de preços de 136,2\%. Nesse mesmo cenário, para uma TIR de $6 \%$ ao ano, o nível de preço real deve aumentar $58,1 \%$. Com a redução de desperdício e implementação dos tratos silviculturais (Cenário E), o nível geral de preços deve elevarse em $97 \%$ e $34,5 \%$ para alcançar a TIR de $12 \%$ e $6 \%$, respectivamente.

Tabela 11. Variação nos preços das toras para obter TIR de $6 \%$ e 12\% ao ano nos três cenários analisados.

Table 11. Variation on $\log$ prices to obtain TIR of $6 \%$ and $12 \%$ per year in the three analyzed scenarios.

\begin{tabular}{lcc}
\multirow{2}{*}{ Cenário } & \multicolumn{2}{c}{ Rentabilidade } \\
\cline { 2 - 3 } & $\mathbf{6 \%}$ & $\mathbf{1 2 \%}$ \\
\hline Cenário C & $+34,5$ & $+137,4$ \\
Cenário D & $+58,1$ & $+136,2$ \\
Cenário E & $+34,5$ & $+97,0$ \\
\hline
\end{tabular}

Fonte: Timofeiczyk (2004).

Cenário C: $12 \mathrm{~m}^{3} / \mathrm{ha}$ nos dois ciclos, sem tratos silviculturais; Cenário D: $12 \mathrm{~m} / \mathrm{ha}$ no primeiro ciclo e $15 \mathrm{~m}^{3} /$ ha no segundo ciclo, com tratos silviculturais; Cenário E: $15 \mathrm{~m}^{3} /$ ha no primeiro ciclo e $18 \mathrm{~m}^{3} /$ ha no segundo ciclo, com tratos silviculturais.

Diante dessa realidade, o grande desafio na região amazônica é oferecer alternativas para combater a destruição das florestas, ocasionadas pela extração ilegal e pela conversão do uso da terra para outros fins. Existem políticas de ocupação e uso da terra que possibilitam aos produtores comercializar a madeira de suas propriedades a baixos preços, de forma a auferir recursos para o desenvolvimento de outras atividades. Também é comum na região a conversão clandestina de grandes áreas para fins agropecuários, após a retirada da madeira.

A implementação do manejo de baixo impacto em escala empresarial requer um alto investimento, bem como uma área extensa de terra. $\mathrm{O}$ baixo preço das madeiras tropicais e a reduzida rentabilidade econômica desencorajam os empresários a exercerem a exploração dos recursos florestais de baixo impacto, para a qual um dos requisitos é a legalidade da terra. Os empresários não estarão dispostos a investir no manejo diante das incertezas do mercado e em relação à posse da terra.

$\mathrm{Na}$ simulação de investimento realizada, verificou-se que em todas as situações em que o investimento em terra foi considerado, a TIR ficou abaixo do esperado. Mesmo nos cenários em que houve aumento da produção, a elevação da TIR e do VPL foi baixa, não sendo suficientes para aumentar a atratividade, demonstrando o grande impacto que o valor do recurso terra tem na viabilidade econômica do manejo.

FLORESTA, Curitiba, v. 38, n. 4, p. 711-725, out./dez. 2008. 
Observa-se na tabela 12 que, havendo investimento em terras, em todos os cenários houve necessidade de uma grande redução no seu valor para aumentar a rentabilidade do manejo. No cenário de maior produção (Cenário E), para se obter a rentabilidade de $6 \%$ ao ano, o valor de mercado da terra deve ser $68,6 \%$ inferior ao praticado na região. Para uma TIR de $12 \%$ ao ano, a redução no valor desse recurso deve ser da ordem de $90,4 \%$.

Tabela 12. Variação no valor da terra para obter TIR de $6 \%$ e $12 \%$ ao ano nos três cenários analisados.

Table 12. Variation on land value to obtain TIR of $6 \%$ and $12 \%$ per year in the three analyzed scenarios.

\begin{tabular}{lcc}
\hline \multirow{2}{*}{ Cenário } & \multicolumn{2}{c}{ Rentabilidade } \\
\cline { 2 - 3 } & $\mathbf{6 \%}$ & $\mathbf{1 2 \%}$ \\
\hline Cenário C & $-89,2$ & $-98,9$ \\
Cenário D & $-87,5$ & $-99,5$ \\
Cenário E & $-68,6$ & $-90,4$ \\
\hline Fonte: Timofeiczyk (2004). & \\
Cenário C: $12 \mathrm{~m}^{3} /$ ha nos dois ciclos, sem tratos silviculturais; Cenário D: $12 \mathrm{~m}^{3} /$ ha no primeiro \\
ciclo e $15 \mathrm{~m}^{3} /$ ha no segundo ciclo, com tratos silviculturais; Cenário E: $15 \mathrm{~m}^{3} / \mathrm{ha}$ no primeiro ciclo \\
e $18 \mathrm{~m}^{3} /$ ha no segundo ciclo, com tratos silviculturais.
\end{tabular}

Esses conjuntos de fatores negativos impõem uma preferência temporal em obter o máximo lucro no presente, em prejuízo da sustentabilidade futura. Isso ocasiona um círculo vicioso, induzindo a uma grande oferta de madeira, pressionando para baixo o preço das toras, e, como conseqüência, gera ineficiência nos processos de extração, transporte e transformação da madeira.

Para reverter esse quadro, devem ser implantadas políticas que estimulem o uso de madeira oriunda de planos de manejo, bem como evitar a destruição de florestas geradas pela ilegalidade e pela conversão do uso da terra para outros fins, assim como melhorar a eficiência e o controle por parte do governo. Essas conclusões mostram a importância do Estado em definir estratégias de ocupação territorial, visando aprimorar as formas de uso e de monitoramento dos recursos naturais de modo a obter a sustentabilidade.

\section{CONCLUSÕES}

Com investimentos em terra, ocorreram piores resultados na TIR e VPL, demonstrando a grande importância do valor da terra na rentabilidade do manejo. Com esse investimento, a TIR e o VPL ficaram muito abaixo da TMA, com o VPL mostrando-se muito sensível ao valor da terra.

A exclusão do valor da terra do investimento promoveu uma melhora significativa na TIR e no VPL, demonstrando o grande impacto que esse recurso teve na análise de projetos de manejo.

A execução da limpeza de estradas secundárias e esplanadas melhoraram a rentabilidade econômica da empresa.

As análises econômicas do manejo devem eventualmente contemplar mais de um ciclo de produção, considerando que os custos que são gerados no primeiro ciclo são compensados muitas vezes em contrapartida por receitas originadas no segundo ciclo.

A análise de sensibilidade mostrou que a TIR foi mais sensível às variações nos preços das toras do que os custos de produção.

\section{REFERÊNCIAS}

ACSELRAD, H. Sustentabilidade, discursos e disputas. In: WORKSHOP Sustentabilidade: Perspectivas Não-Governamentais, 1995, Rio de Janeiro. Anais... Rio de Janeiro: IBASE, 1995.

AMARAL, P.; VERÍSSIMO, A.; BARRETO, P.; VIDAL, E. Floresta para sempre: um manual para a produção de madeira na Amazônia. Belém: Imazon, 1998. 130 p.

ANGELO, H. As exportações brasileiras de madeiras tropicais. 129 f. Tese. (Doutorado Engenharia Florestal) - Setor de Ciências Agrárias, Universidade Federal do Paraná, Curitiba, 1998. 
ANGELO, H.; PRADO, A. C.; BRASIL, A. A. Influência do manejo florestal e do desmatamento na oferta de madeiras tropicais na Amazônia brasileira. Revista Ciência Florestal, Santa Maria, RS, 2004 (No prelo).

BARRETO, P.; AMARAL, P.; VIDAL, E.; UHL, C. Custos e benefícios do manejo florestal para a produção de madeira na Amazônia Oriental.. Belém: Imazon, 1998. 48 p. (Série Amazônica, n.10).

CASAROTTO, N. F.; KOPITTKE, B. H. Análise de investimentos. 6 ed. São Paulo: Atlas, 1994.

CUNHA, U. S. Análise da estrutura espacial horizontal de uma floresta de terra firme da Amazônia. 126 f. Tese (Doutorado em Engenharia Florestais) - Setor de Ciências Agrárias, Universidade Federal do Paraná, Curitiba, 2003.

HILDEBRAND, E. Sistema de apropriação e análise de custos para a empresa florestal. $145 \mathrm{f}$. Dissertação. (Mestrado em Engenharia Florestais) - Setor de Ciências Agrárias, Universidade Federal do Paraná, Curitiba, 1995..

HORNGREN, C. T. Introdução à contabilidade gerencial. 5. ed. Rio de Janeiro: Prentice-hall do Brasil, 1985.

KASSAI, J. R.; KASSAI, S.; SANTOS, A.; ASSAF NETO, A. Retorno de Investimento: abordagem matemática e contábil do lucro empresarial. 2 ed. São Paulo: Atlas, 2000.

LIMA Jr., V. B.; REZENDE, J. L. P.; OLIVEIRA, A. D. Determinação da taxa de desconto a ser usada na análise econômica de projetos florestais. Cerne. Lavras, n 1, p. 45-66, 1997.

NORONHA, J. F. Projetos Agropecuários: administração financeira, orçamento e viabilidade econômica. 2 ed. São Paulo: Atlas, 1987.

REZENDE, J. L. P.; OLIVEIRA, A. D. Análise econômica e social de projetos florestais. Viçosa: UFV, 2001.

SIQUEIRA, J. D. P. Proposta para a melhoria da comercialização. Projeto UTF/BRA/047 - Agenda Positiva para o Setor Florestal do Brasil. Brasília, DF: MMA, 1999. 60 p.

SOUZA, A. L. P. Desenvolvimento sustentável, manejo florestal e o uso dos recursos madeireiros na Amazônia: desafios, possibilidades e limites. Belém: UFPA/NAEA, 2002. 255 p.

TIMOFEICZYK Jr., R. Análise econômica do manejo de baixo impacto em florestas tropicais - um estudo de caso. 126 f. Tese (Doutorado em Engenharia Florestais) - Setor de Ciências Agrárias, Universidade Federal do Paraná,. Curitiba, 2004.

YARED, J. A. G. Análise dos projetos de manejo de florestas naturais na Amazônia oriental: aspectos silviculturais, ecológicos e de legislação. Viçosa, MG: Universidade Federal de Viçosa, 1992. 